\title{
Atrial thrombus masquerading as atrial myxoma: Preliminary analysis of echocardiographic findings
}

fang song ${ }^{1}$ and guobing $\mathrm{hu}^{1}$

${ }^{1}$ no affiliation

November 17, 2021

\begin{abstract}
We retrospectively analyzed the echocardiographic findings of 8 patients with atrial thrombus (AT). This study was conducted in Yijishan Hospital between January 2019 and September 2021. Of the 8 patients, right atrial mass was detected in 4 patients, and left atrial mass was detected in the rest 4 patients. All masses were initially diagnosed as myxoma, which were later confirmed as thrombus. Athough echocardiography can provide significant information about the nature of atrial mass in many patients, a small percentage of atrial masses remain difficult to make a qualitative diagnosis.
\end{abstract}

\section{Hosted file}

text.doc available at https://authorea.com/users/446693/articles/545864-atrial-thrombusmasquerading-as-atrial-myxoma-preliminary-analysis-of-echocardiographic-findings
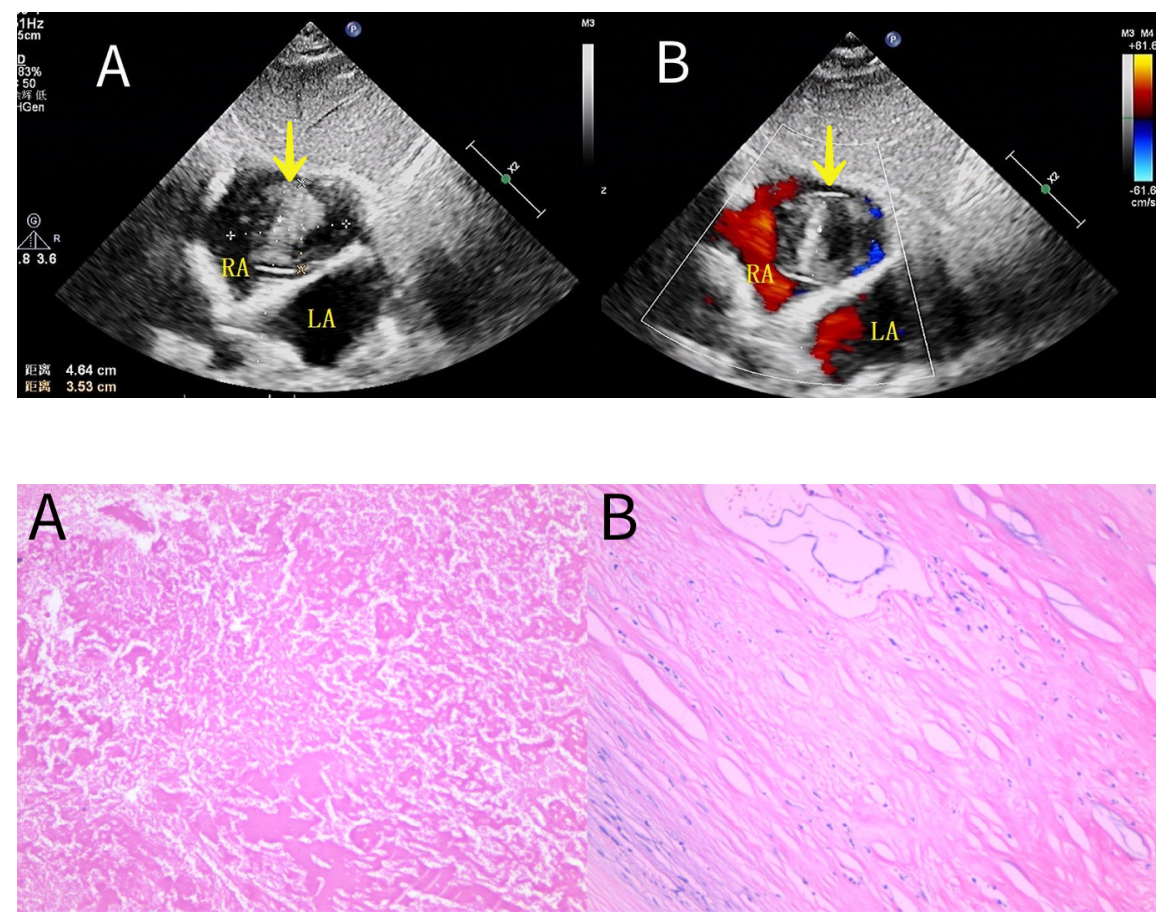

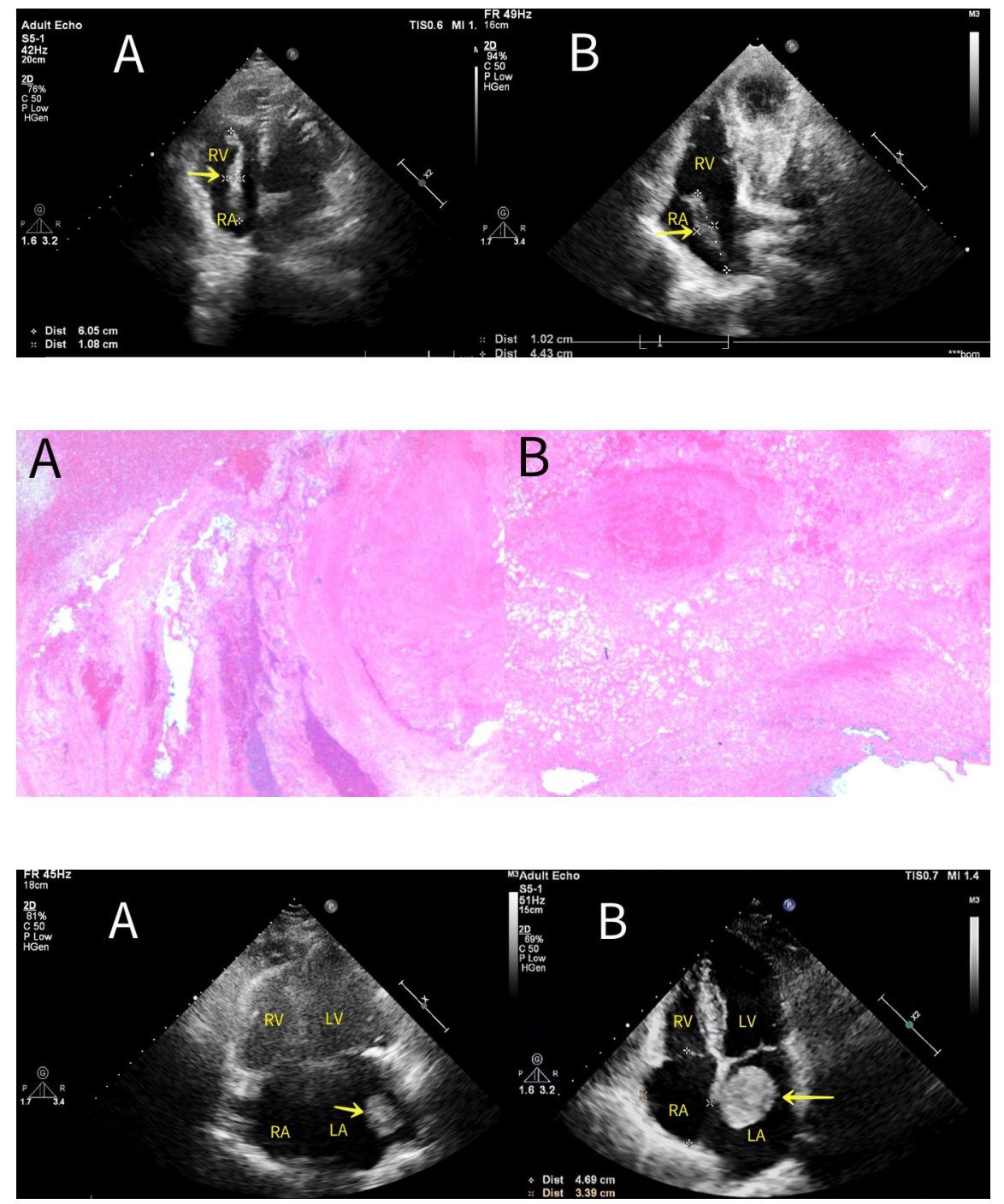

\section{Hosted file}

table 1.doc available at https://authorea.com/users/446693/articles/545864-atrial-thrombusmasquerading-as-atrial-myxoma-preliminary-analysis-of-echocardiographic-findings 